Journal of Social Sciences 5(1): 22-24, 2009

ISSN 1549-3652

(C) 2009 Science Publications

\title{
Social Capital Concerning a Conservation of Sweet Wild Trees (Phak Whanpa) in a Northeastern Thailand Community
}

\author{
${ }^{1}$ Phiphaporn Ravipolsadtanan, ${ }^{2}$ Worapol Aengwanich and ${ }^{3}$ Prasopsuk Littidet \\ ${ }^{1}$ Research Institute of NE Art and Culture, Mahasarakham University, Thailand, 44000 \\ ${ }^{2}$ Department Faculty of Science, Mahasarakham University, Thailand, 44000 \\ ${ }^{3}$ Faculty of Humanities and Social Science, Rajabhat Mahasarakham University, Thailand, 44000
}

\begin{abstract}
Problem statement: Thai people favored to eat Sweet Wild Trees (Phak Whan Pa). The wild trees naturally grew quite slowly in the forests. Their leaves, eaten as vegetables, could not meet market demand nationwide. Seedling was difficult and people were not interested in planting them. Support from government and/or public sectors was slow. Those were the causes for shortages of the sweet wild trees. The purpose of the study was to study the social capital concerning a conservation of sweet wild trees. Approach: The study was carried out at Sakarat community located in Amphoe Pak Thong Chai Nakhonratchasima. As a qualitative research, documentary and field work data were collected. The 10 informants were planters and government officials responsible for conservation of the sweet wild trees at the Sakarat Environment Research Office. The research results were presented descriptively. Results: The social capitals, to a large extent, arose from shortages of the sweet wild trees, Known as, Phak Whan Pa, in Northeastern Thailand. Yet, the leaves of Phak Whan Pa were not only popular among the Thai people but also they were more expensive than other wild and home grown vegetables. A conservation of these given plants by planting them in their community and near by woods was proposed, implemented and endorsed by community leaders and Buddhist monks. Their objective as an interest group was to grow herbal plants at the Klongtery temple by giving 2-3 Phak Whan Pa seedlings to each family in the community turning such a maneuver a social capital. They often held meetings and spared news in community media, known as, Hor Krajai Kao. Tourist and learning programs were carried out at the Sakarat Environment Research office, such as, planting young plants or seedlings in the community forests protecting them with wooden cages and providing cares so that they survived in own natural setting. Conclusion/Recommendations: The people in the community and near by were allowed to pick the Phak Whan Pa in their community forests and the Taplan National Park. Keeping in mind that a conservation and awareness of the popular wild plants finally paid off and benefited to all concerned people.
\end{abstract}

Key words: Social capital, sweet wild plants (Phak Whan Pa), Northeastern Thailand

\section{INTRODUCTION}

The sweet wild plants or Phak Whan Pa are plant food and very popular in the Northeastern Thailand. Being wild plants and popular as they are, their leaves grown could not meet the market demand. The plants themselves grew quite slowly even in natural setting; both natural and artificial seedlings were difficult to achieve. Support from government and/or public sectors was slow. Some people tried to plant the plants on their land but met with some success due to lack of practical skills. The Sakarat community tried an experiment by planting the sweet wild plants in the community forests and the ones near by making such a maneuver a social capital. From then on the wild plants were valued highly; the people made them part of their own community.

\section{MATERIALS AND METHODS}

The history of social capital for the sweet wild plants at Sakarat community: At the Sakarat community, there was an ancient Khmer ruin, known as, Prang Ku Kasem or Prasat Bung Kham with a symbol of Linka ${ }^{[1]}$ In 1609, some people from Vientiane moved to settle there calling their new settlement "ban koke" meaning a bountiful forest. There was a special kind of trees, the people called them Phak Whan Pa or sweet wild trees.

Corresponding Author: P. Ravipolsadtanan, Research Institute of NE Art and Culture, Mahasarakham University, Mahasarakham, 44150, Thailand Tel: +66-43-742827 Fax: +66-43-742827 


\section{J. Social Sci., 5(1): 22-24, 2009}

The people picked their leaves for food. The trees grew naturally well near and on the mountains. Not only there were not plenty of them that could grow quite slowly but also their edible and young leaves could be picked only from July-September each year ${ }^{[2]}$. Picking the leaves was allowed at the community forests. Other than that area, picking the leaves was limited especially at the Taplan National Park. Setting up a group of concerned citizens at Sakarat for the sweet wild tree transplanting with in their own community forests built a social capital.

Social capital of Sakarat community: The social capital arose at Sakarat community from an awareness of the sweet wild plants conservation. Some Buddhist monks initiated forest conservation and herbal plants growing on the temple land for the occasion of the King's 60th birthday. The name of the group Teoy Kosol Sakarat Toxic Free herbs. The group had an office at the community temple where they had a rai for planting the trees. They bought the seeds from Saraburi for seedlings. They planted the seedlings on the temple land, then they did on their own land and later to nongroup members in the community. There were 600 sweet wild trees in Sakarat community. The trees are natural resources, social capital and are providing an ecological nitch of edible plant food. Each membered- family had their own leaves for food as well as for sell.

Community internal communication process: The social capital arose from the community internal communication process. The village leader often held meetings, posted news or made announcements publicizing the Phak Whan $\mathrm{Pa}$ planting in their community forest and private land. The publicity of Phak Whan $\mathrm{Pa}$ included the awareness and cares of trees and forests. The people at the Sakarat community must not either did it them selves or provided support for others to do it, such as, cut down trees, took home with them certain objects that were banned by the authority, caused forest fires, or dug up the Phak Whan Pa young plant of plants from the Taplan National Park for sell or own use. The people were advised these cautions through the community news center or Hor Krachai Kao. The Buddhist monks at Wat Khao Trakud Rang also helped publicizing the conservation of Phak Whan Pa using a Buddhist guide line emphasizing the important role of natural forests and tree transplanting on private and the temple lands. Through such learning by doing strategy, the people were fully aware of the conservation of Phak Whan Pa.
The outside social capital: The social capital for a conservation of Phak Whan Pa of Sakarat community came about using various means. First, they got direct learning experience from the Sakarat Environment Research office, such as, how to do the seedlings, planting young trees, giving water and organic fertilizer, twice yearly. Second, they built forest fire protection zone. Forest fires often caused by low humidity during the dry season. Some hunters and gatherers often caused forest fines for better visibility and animal chases. Some farmers, whose lands were close to the forests, burnt weeds and what was left over from previous harvest, also caused forest fires. Once occurred, most forest fires were difficult to put out. The people at the Sakarat community and authority personnel together asked the people to make fire protection zones. The sweet wild trees as well as all other forest trees grew naturally well allowing people to pick tree leaves for food, take a walk or sightseeing.

Community eco-tourism: The Sakarat Environment Research Office operated an eco-tourist service offering accommodations for 150 persons. At the sightseeing area, visitors could observe natural surrounding, such as, trees, wild animals, insects and night stars. Visitors were also provided with information concerning the significant roles and usage of the forests and a conservation of the sweet wild trees or Phak Whan Pa. If visitors were interested in plant studies including plant propagation, they could do so at the Lamthakhong Research Office located at Amphoe Pak Chong. If they still had time, they could visit the Teoy Kosol Sakarat Toxic Free herbal garden. They could buy the young plants of Phak Whan $\mathrm{Pa}$ to grow on their own land, government and/or private land.

Taking care of the wild young trees: Natural surroundings, such as, forests and sweet wild trees brought peaceful and refreshing environment to the community. The Sakarat Environment Research Office found that Phak Whan $\mathrm{Pa}$ did propagate in natural settings of nearby forests and private lands. For security reason, an iron fence around each young tree, some young trees were about 5 inches tall. Most of them were grown under larger trees. They were better off than the ones that received none of the water, fertilizer and weed control provided by the office. The people there learned that the sweet wild trees could be conserved and propagated in natural settings. They treated such trees as if they had heart and mind like people. 
The study was carried out at Sakarat community located in Amphoe Pak Thong Chai Nakhonratchasima. As a qualitative research, documentary and field work data were collected. The 10 informants were planters and government officials responsible for conservation of the sweet wild trees at the Sakarat Environment Research Office. The research results were presented descriptively.

\section{RESULTS}

There were the sweet wild trees in the fertility forest at the Sakarat ancient community. The wild trees naturally grew quite slowly in the forests. The villagers conserved these plants by planting them in their community. The Social capital of Sakarat community had 2 processes were (1) Community internal communication by cooperation of the villagers, the monks and the community leaders planted the sweet wild trees at the herbs planting group, temple and lands. Using the communication process from the state policies to conserve the environments by planting the sweet wild trees. (2) The outside social capital by the villagers and the official of research institute promoted to plant and conserve the sweet wild trees by making fire protection zones. The Sakarat Environment Research Office operated an eco-tourist service. The sweet wild trees as well as all other forest trees grew naturally well allowing people to pick tree leaves for food, take a walk or sightseeing.

\section{DISCUSSION}

The social capital concerning of conservation of the sweet wild trees at Chum Chon Ban Sakarat was agreed with the findings of the study by ${ }^{[3]}$ which stated that the communication process supported the planting the sweet wild trees for consumption and sale and the villagers cooperated to conserve the sweet wild trees in the forest and plant it in the community. Their green community was the sufficient economic by conservation the sweet wild trees and others vegetables $^{[3]}$.

\section{CONCLUSION}

It was the social capital that led the Sakarat community to conserve the sweet wild trees or Phak Whan Pa. It all began with the ecological problems the community was facing at that time-the number of the Phak Whan Pa trees was decreasing drastically and so was the green areas. Their bringing back the trees, for the Sakarat people not only brought economic plants but also the natural resource they were closely related. The trees brought learning experience, organizations, self-learning ${ }^{[3]}$, the green areas and interdependence between people and natural forests.

To conserve Phak Whan Pa or sweet wild trees and make them economic plants needs strong support among concerned people and various offices. As the Sakarat Environment Research Office produced more seedlings of the trees, other government offices, such as, Agriculture Office, Community Development Office/District Administrative Organization, should come up with budget for publicity, marketing and transplanting. The plants were actually good for the communities nearby in terms of economic gains and conservation idea of environment.

\section{ACKNOWLEDGEMENT}

The researchers express their sincere appreciation for all of support provided and the referees for their helpful comments.

\section{REFERENCES}

1. Pantasen, A., P. Piampongsan, T. Pantasen and S. Piamyad, 2007. The Knowledge Synthesis of Sufficient Economic. The Research Funds Office, pp: 312. ISBN: 974-9666-94-1.

2. Nartsupha, C., 2003. The Thai village economy in the past. J. Econ. History, 63: 265-266. DOI: 10.1017/S0022050703331808

3. Kaewtep, K., 2004. Communication for Beautiful World: The Lesson from Communication to Manage the Environment in Community. 1st Edn., Seven Printing Group Ltd. Press, ISBN: 97494198-6-3, pp: 280. 